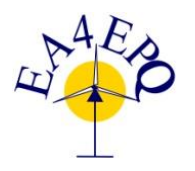

International Conference on Renewable Energies and Power Quality (ICREPQ’18)

Salamanca (Spain), $21^{\text {th }}$ to $23^{\text {th }}$ March, 2018

Renewable Energy and Pourer Quality. Fournal (RE\&PQJ)

ISSN 2172-038 X, No.16 April 2018



\title{
Solar Energy Potential and Time of Use Tariffs: a study case for São Luiz do Paraitinga
}

\author{
Gheisa R.T. Esteves ${ }^{1}$, Marco A. Cunha ${ }^{1}$, Wesley Fagundes ${ }^{1}$, Reinaldo C. Souza ${ }^{1}$, Alexandre da Silva ${ }^{4}$ \\ ${ }^{1}$ Pontifical Catholic University of Rio de Janeiro - PUC-Rio \\ Rua Marquês de São Vicente, 225 \\ Edifício Cardeal Leme, 9th Floor - Gávea \\ Rio de Janeiro - RJ - (Brazil) \\ Cep: $22451-900$ \\ Phone/Fax number: +(005521) $3527-1001$ \\ e-mail: gheisae@gmail.com, macfe@ele.puc-rio.br,wesley@puc-rio.br, reinaldo@ele.puc-rio.br \\ ${ }^{2}$ Elektro - Electricity Distribution Company \\ Pontifical Catholic University of Rio de Janeiro - PUC-Rio \\ Rua Ary Antenor de Souza, 321. Campinas - SP (Brazil) \\ Email: alexandre.dasilva@elektro.com.br
}

\begin{abstract}
Brazil has one of the highest solar energy potential in the world, but despite of that, both distribution companies and consumers does not take advantage of it as a whole. Aligned with this there is an increasing interest on improving the consumers' knowledge and perception of energy costs. Brazilian electricity regulation conceived, during the last 7 years the entire regulatory framework needed to promote and support solar energy use and reformulated tariffs structures enabling the introduction of time-ofuse (TOU) tariffs to low voltage consumers in 2018. Therefore, it is important to understand the impact of both changes on an electricity market. That is the article's main goal, to understand the potential and impact of solar energy and TOU tariffs, for residential consumers using computational intelligence techniques and statistical analysis.
\end{abstract}

Keywords: solar energy, time of use tariff, white tariff, fuzzy logic, distributed energy.

\section{INTRODUCTION}

Solar energy use and time-of-use tariffs applied and available for low voltage consumers is already a reality in most European Countries [1-6]. In Brazil, despite of having one of the highest solar energy potential in the world, its use of solar energy is still incipient [7-6]. Time-of-use tariffs for low voltage consumers will soon become a reality, therefore both distribution companies and consumers need to understand the impact of new technologies and policies on the electricity market. Aligned with this there is an increasing interest, by the Electricity Regulator, to improve consumers' knowledge and perception of energy costs and how their use behavior reflects on energy prices. Brazilian electricity regulator conceived, during the last 7 years the entire regulatory framework needed to promote and support solar energy use and reformulated tariffs structures enabling the introduction of time-of-use (TOU) tariffs for low voltage consumers in 2018. Therefore, it is important to understand the impact of both changes on an electricity market. That is the article's main goal: to understand the potential and impact of solar energy and TOU tariffs, for residential consumers, using computational intelligence techniques and statistical analysis. To do, the study makes a study case for a small city in São Paulo State (Brazil), called São Luiz do Paraitinga, using month information from real-time load demand curves for a sample of residential consumers. Through the typical load curves of each consumer sampled, solar energy generation potential and the impact of the TOU tariffs (to be applied in 2018) was estimated for the whole city.

The article is divided into five sections. The first section contains the introduction to the subject and the motivations of the study. The second section describes the method applied to develop the study, considering the procedures used to define the sample size and consumers selection and to estimate solar energy potential and the impact of TOU tariff. The third section gives an overview of the electricity market of São Luiz do Paraitinga and defines sample size and the neighborhoods where consumers where selected. In the fourth section both, the results for solar energy generation potential and TOU tariff 
impact are presented. The fifth section presents the main conclusions and possible future research implementations.

\section{MethodOLOGY}

The sampling technique applied during the study was a stratified sampling, where the stratification was made considering residential consumer's monthly average consumption. The stratification levels where the ones considered by the electricity regulator on its measurement campaigns. Figure 1 presents the stratification used for the average electricity consumption.

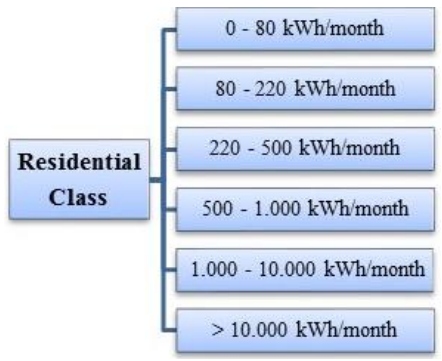

Figure 1. Stratification Structure

Figure 2 contains the study method flowchart. The first step is to calculate the sample size, select consumers, which the daily load demand curves will be collected, validate the load curves and define typical load curves for each consumers sampled. Through the typical load curves, for business and non-working days, calculated for each consumers, the solar energy generation potential and TOU tariff impact estimation is obtained.

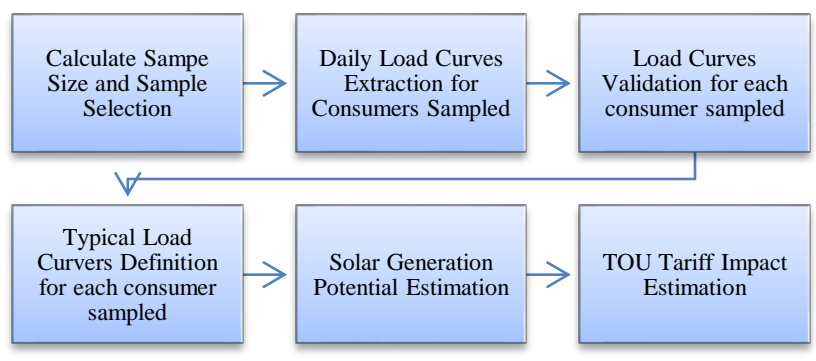

Figure 2. Study Procedures Flowchart

The mathematical formulation used to calculate the sample size is the following:

$$
n=\sum \frac{1,96^{2} \cdot\left(\frac{C V_{j, k}}{R}\right)^{2}}{1+\frac{1,96^{2}}{R} \cdot\left(\frac{C V_{j, k}}{R}\right)^{2}}
$$

Where:

$C V_{j, k}$ : variation coefficient for the average monthly electricity consumption for the stratum $\mathrm{j}$ in the consumer class $\mathrm{k}$

$R$ : sampling error

$n$ : sample size

The $C V$ is the variable used to estimate the stratum variability, as presented below:

$$
C V_{j, k}=\frac{s_{j, k}}{\bar{x}_{j, k}}
$$

Where:

$$
s_{j, k}=\frac{1}{N_{j, k}} \sum_{i=1}^{n}\left(x_{i j, k}-\bar{x}_{j, k}\right)^{2}
$$

And,

$s_{j, k}$ : monthly average consumption standard deviation in the stratum $\mathrm{j}$ and consumer class $\mathrm{k}$

$\bar{x}_{j, k}:$ monthly average consumption in the stratum $\mathrm{j}$ and consumer class $\mathrm{k}$

$x_{i_{j, k}}$ : monthly average consumption for the consumer $\mathrm{i}$ which belong to the stratum $\mathrm{j}$ and consumer class $\mathrm{k}$

$N_{j, k}$ : number of consumers in the stratum $\mathrm{j}$ and consumer class $\mathrm{k}$

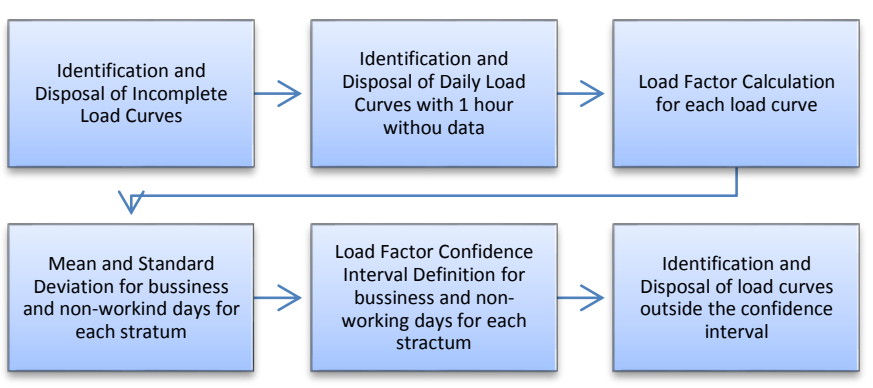

Figure 3. Load Curves Validation Procedure

With the load curves collected, the second step is to validate the daily load curves, to guarantee the analysis consistency. Therefore, each daily load curve received passed through the validation procedure presented at Figure 3. The remaining load curves are used to define typical load curves for each consumer sampled for business and non-working days. For the typical load curve definition an index, named " $Z$ ", is calculated:

Where:

$$
Z_{c_{n}, i}=D_{\operatorname{Max}_{c_{n}, i}} \times D_{M d_{c_{n}, i}}, i=1,2, \ldots, m ; n=1,2, \ldots, k
$$

$Z_{c_{n}, i}$ : index " $Z$ " for the load curve " $\mathrm{n}$ " from the consumer $\mathrm{i}$

$D_{\operatorname{Max}_{c_{n}, i}}:$ maximum demand for the load curve " $\mathrm{n}$ " from the consumer i

$D_{\text {Med }_{c_{n}, i}}$ : average demanda for the load curve " $\mathrm{n}$ " from the consumer i

The typical load curve for business and non-working days are the ones with the highest " $Z$ ".

Thereby, in the end of the load curves analysis, there is three situations:

- The consumer remains with three load curves: one for business days, one for Saturday and one for Sunday

- The consumer remains with two load curves: one for business days and one for non-working days

- The consumer remains with only one load curve: one for business days or one for non-working days

- The consumer remains with no load curves: one for business days and one for non-working days 
Only consumers with at least one typical load curve for nonworking days and typical load curve for business day will be considered to estimate the solar energy generation potential and the TOU tariff impact. Therefore consumers with only one load curve and no load curve are disposed.

\section{A. Solar Energy Potencial Estimation Method}

To estimate the solar energy potential is determined using fuzzy logic techniques in the typical load curves of each consumer sampled. To classify each typical load curve according to its technical potential for solar energy generation, it's compared with São Luiz do Paraitinga mean solar radiation incidence curve, provided by National Institute of Meteorology (INMET).

The fuzzy methodology applied in the study was developed by Carmo [7-8] and classifies the load curves according with its technical potential to solar energy generation using fuzzy logic techniques. Firstly, three different solar radiation incidence levels through thought the day are identified with data from the mean solar radiation incidence curve. Then the next step is to define the fuzzy sets related to each one of the three radiation levels. To do so, energy consumption index (IC) are calculated for each consumer typical load curve using the mathematical formulation presented below, where the ratio between the average consumption in each radiation incidence level and the total average consumption is determined.

$$
I C_{N, x}=\mu_{N, x} / \mu_{T, x}
$$

Where:

$I C_{N, x}$ : energy consumption index for the hour in $\mathrm{N}(\mathrm{N}$ can be a period of minimum radiation, maximum radiation or intermediate radiation) for the consumer $\mathrm{x}$

$\mu_{N, x}$ : mean energy consumption for the hour in $\mathrm{N}$ for the consumer $\mathrm{X}$

$\mu_{T, x}$ : mean total consumption for the consumer $\mathrm{x}$

The fuzzy system input sets are determined for each IC with two methods: total amplitude and quartiles method. The fuzzy set then passes through a set of rules defined by a Mandani fuzzy inferential system [12] and a membership function is conceived and, then, through this function, each typical load curve is classified in one of the five classes of solar energy generation potential:

- Class 1: consumers with lowest potential, i.e., load curves where there is very little or no consumption during periods of high solar radiation incidence. Class with the lowest solar energy potential;

- Class 2: consumers with low potential, i.e., load curves with little energy consumption during periods of high solar radiation incidence.

- Class 3: consumers with medium potential, i.e., load curves with considerable energy consumption during the periods of high radiation incidence.

- Class 4: consumer with high potential, i.e., load curves where most of part of the energy consumption occurs during the periods of high solar radiation incidence.
- Class 5: consumers with the highest potential, i.e., load curves where the energy consumption is almost totally centralized during the periods of high solar radiation incidence.

With all the load curves classified by solar energy potential, the last step comprehends the transformation of the fuzzy variables into crisp results using the defuzzification process named Middle of Maximum - MOM. In other words, at this stage the load curves are classified according with the output derived from the membership function intervals.

\section{B. TOU Tariff Impact Analyis}

To estimate the TOU tariffs impact on residential consumers the typical load curves of each consumer is used. Figure 4 show the procedure step by step. The first step consists of collecting residential flat and TOU tariffs information for São Luiz do Paraitinga to be able to calculate, for each consumer, the electricity costs considering each one of the tariffs. The tariff that each consumer suits better is the one least costly, thus, it is possible to identify in which tariffs each consumer sampled fits better. Then, with the estimation of the TOU tariffs impact on the consumers sampled, it is possible to estimate the impact considering all residential consumers.

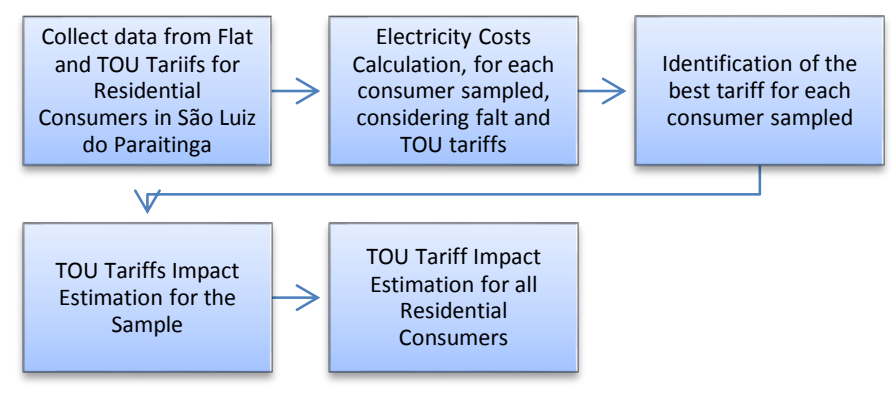

Figure 4. TOE Impact Analysis

\section{DATASET AND SAMPLING}

São Luiz do Paraitinga is a city with 5.921 electricity consumers among which $75 \%$ are residential consumers and approximately $10 \%$ are "public service" consumers. Most of the consumers are concentrated on five neighborhoods: City Centre (20\%), Bro São Benetido (7\%), Alto do Cruzeiro, Benfica $(6,5 \%)$ e o Catucaba District $(4,3 \%)$.

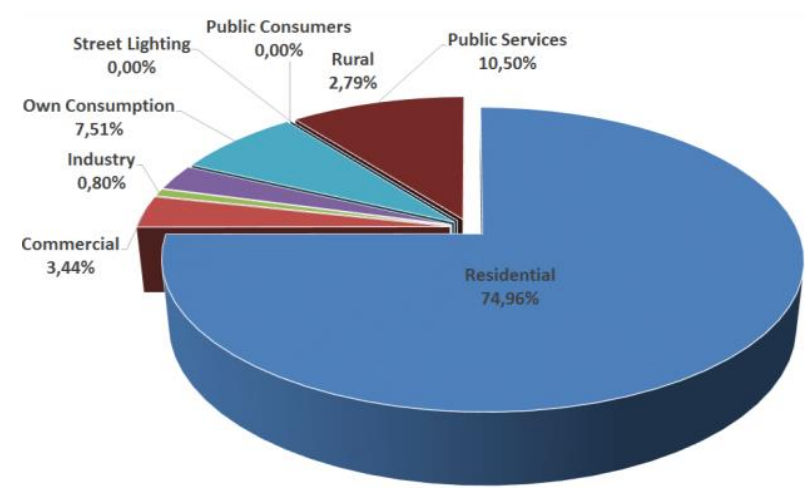

Figure 5. Low Voltage Consumption Share 
The city annual electricity consumption, in 2016, was 12,6 $\mathrm{GWh}$, and residential consumers are responsible for around $41,50 \%$ of the city electricity market, followed by the rural and commercial consumers, with $44,37 \%$ and $14,24 \%$, respectively. The neighborhoods which most consumes are: city centre $(20,7 \%)$, Bro São Benedito $(7,4 \%)$, Alto do Cruzeiro (4,4\%), Benfica (\%) e Bro Rio Acima $(3,4 \%)$.

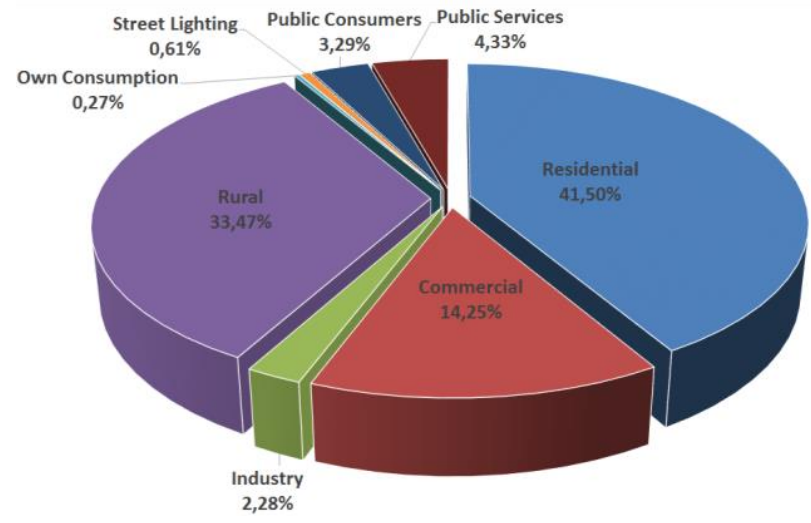

Figure 6. Low Voltage Consumption Share

Considering the energy consumption intervals presented at Figure 1, most residential consumers consumes no more than $220 \mathrm{kWh} /$ month $\left(1^{\circ}\right.$ e $2^{\circ}$ stratum), but more than half of the city electricity consumption belongs to the $2^{\circ}$ stratum (Table 1 ). The first and third stratum are responsible for around $18 \%$ of the electricity consumption each (Figure 17). In other words, $92,50 \%$ of the city electricity consumption belongs to consumers from the first, second and third stratum.

TABLE I. RESIDENTIAL CONSUMERS MARKET ANALYSIS

\begin{tabular}{|c|c|c|c|c|c|c|c|}
\hline $\begin{array}{l}\text { Consumer } \\
\text { Class }\end{array}$ & Group & Stratum & $\begin{array}{c}\text { Consumption } \\
\text { Interval }\end{array}$ & Consumers & $\begin{array}{l}\text { Consumer's } \\
\text { Share }\end{array}$ & $\begin{array}{l}\text { Consumption } \\
\text { (kWh) }\end{array}$ & $\begin{array}{c}\text { Market } \\
\text { Share }\end{array}$ \\
\hline \multirow{6}{*}{ Residential } & 1 & 1 & 1 - 0 A 80 & 1.914 & $46,1 \%$ & 993.215 & $18,5 \%$ \\
\hline & 1 & 2 & $2-81$ A 220 & 1.930 & $46,5 \%$ & 3.023 .929 & $56,3 \%$ \\
\hline & 1 & 3 & 3-221 A 500 & 278 & $6,7 \%$ & 949.131 & $17,7 \%$ \\
\hline & 1 & 4 & $4-501$ A 1000 & 19 & $0,5 \%$ & 153.302 & $2,9 \%$ \\
\hline & 1 & 5 & $5-1001$ A 10000 & 14 & $0,3 \%$ & 248.350 & $4,6 \%$ \\
\hline & 1 & 6 & 6-MAIOR 10000 & - & - & - & - \\
\hline \multicolumn{4}{|c|}{ Total Residential } & 4.155 & $70,38 \%$ & 5.367 .927 & $41,50 \%$ \\
\hline
\end{tabular}

Table 2 presents the sample calculated considering a $20 \%$ sample error and Table 3 show the number of consumers whose load curves were actually collected. As there were some issues to collect data from consumers belonging to the fourth and fifth stratum (load curves measurements quality and some consumers registered as residential were, in fact, commercial consumers), those measurements were displaced and more samples were added in the first, second and third stratum. Adding more samples to those stratum aims improve the estimates for the residential consumers' behaviors.

The consumers sampling selection focused on the neighborhoods responsible for most of the city electricity consumption and all the load curves collected were analyzed following the procedure presented at Figure 3. Therefore, from the 176 consumers sampled, 16 were disposed during the validation process. Another 4 consumers did not match the final criteria (did not have, at least one business day and one non-working day load curve) and were discarded.

TABLE II. SAMPLE CALCULATION

\begin{tabular}{|ccccrrrr}
$\begin{array}{c}\text { Consumer } \\
\text { Class }\end{array}$ & Group & Stratum & $\begin{array}{c}\text { Consumption } \\
\text { Interval }\end{array}$ & $\begin{array}{c}\text { Average } \\
\text { Consumption }\end{array}$ & $\begin{array}{c}\text { Standard } \\
\text { Deviation }\end{array}$ & CV & Sample \\
\hline & 1 & 1 & 1-0 A 80 & 43,24 & 20,70 & $48 \%$ & 22 \\
& 1 & 2 & 2-81 A 220 & 131 & 36,59 & $28 \%$ & 8 \\
Residencial & 1 & 3 & 3-221 A 500 & 285 & 62,69 & $22 \%$ & 5 \\
& 1 & 4 & 4-501 A 1000 & 672 & 139,89 & $21 \%$ & 4 \\
& 1 & 5 & 5-1001 A 10000 & 1.478 & 261,19 & $18 \%$ & 3 \\
& 1 & 6 & 6-MAIOR 10000 & - & - & - & \\
\hline \multicolumn{7}{l}{ Total Residential } \\
\hline
\end{tabular}

Table 3 shows the consumers disposed from the sample by stratum and one can see that 14 consumers belongs to the lowest energy consumption level, 7 from the second stratum and 1 from the third stratum. Typical load curves for business and non-working days are estimated for each one of the 154 consumers remaining at the database.

TABLE III. MEASUREMENT ANALYSIS

\begin{tabular}{|c|c|c|c|c|c|c|}
\hline \multirow{2}{*}{$\begin{array}{c}\text { Consumer } \\
\text { Class }\end{array}$} & \multirow{2}{*}{ Group } & \multirow{2}{*}{ Stratum } & \multirow{2}{*}{$\begin{array}{l}\text { Consumption } \\
\text { Interval }\end{array}$} & \multicolumn{3}{|c|}{ Mesurements } \\
\hline & & & & Total & Cleared & Final \\
\hline \multirow{3}{*}{ Residencial } & 1 & 1 & 1.0 A 80 & 74 & 63 & 60 \\
\hline & 1 & 2 & $2-81$ A 220 & 92 & 88 & 85 \\
\hline & 1 & 3 & $3-221$ A 500 & 10 & 9 & 9 \\
\hline \multicolumn{4}{|c|}{ Total Residential } & 176 & 160 & 154 \\
\hline
\end{tabular}

\section{RESULTS}

\section{A. Solar Enery Potential Analysis - Results}

To compare the estimated typical load curves and the solar radiation incidence curve, firstly it is crucial to analyze data from solar radiation incidence itself, in order to determine the parameters to be used in the study.

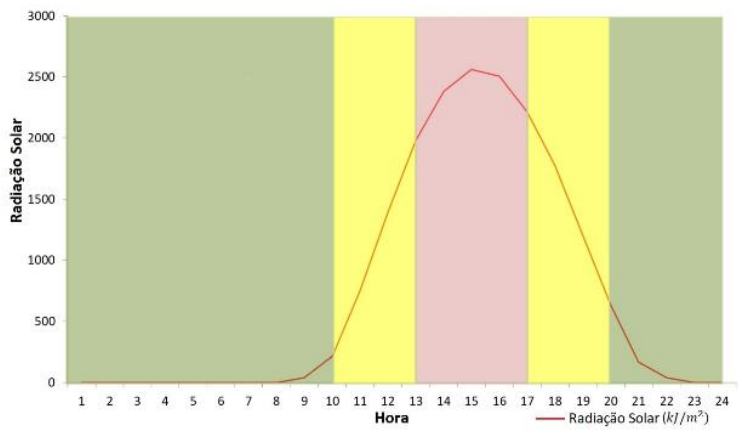

Figure 7. Solar Radiation Incidence Curve

Figure 8 shows the solar radiation incidence curve for São Luiz do Paraitinga, where the area in green corresponds to periods with low radiation level, yellow periods of medium radiation level and pink periods with high radiation levels.

TABLE IV. GLOBAL RADIATION INCIDENCE LEVELS - SÃO LUIZ DO PARAITINGA

\begin{tabular}{cc} 
Levels & Time Interval (h) \\
\hline Minimum Radiation & $20-10$ \\
Intermediate Radiation & $10-13$ e $17-20$ \\
Maximum Radiation & $13-17$ \\
\hline
\end{tabular}


The information presented in Table 4 and Figure 8 is the one needed to calculate the electricity consumption indexes, which are, then, used to determine the fuzzy input sets (Table 5). The fuzzy input sets were defined through a combination of the total amplitude and quartiles method.

TABLE V. FUZZY INPUT SETS

\begin{tabular}{cccc} 
IC & Low & Medium & High \\
\hline \multirow{3}{*}{ Minimum } & 0 & 0,3267752 & 0,7029984 \\
& 0,3267752 & 0,6343521 & 0,9419291 \\
& 0,6535504 & 0,9419291 & 1,4443935 \\
\hline \multirow{3}{*}{ Medium } & 0 & 0,6742036 & 0,7260712 \\
& 0,6742036 & 1,0113054 & 1,3484072 \\
& 1,163788 & 1,348407 & 2,310965 \\
\hline \multirow{3}{*}{ Maximum } & 0 & 0,5670959 & 0,6611773 \\
& 0,5670959 & 0,9447253 & 1,3223546 \\
& 0,932868 & 1,322355 & 2,184856 \\
\hline
\end{tabular}

The fuzzy input sets are analyzed considering the fuzzy systems rules through the membership function (Figure 9).

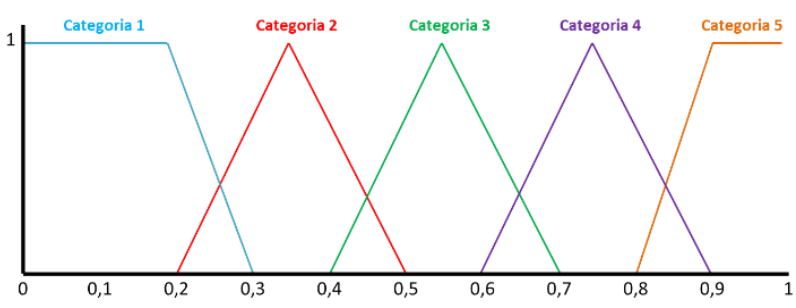

Figure 8. Membership Funcion

The defuzzyfication, made through the MOM method, generated crisp output from the fuzzy variables, so the outputs obtained from the membership function intervals are classified according to the information provided on the Table 6 .

TABLE VI. FUZZY OUTPUT CLASSIFICATION

\begin{tabular}{cl}
\hline Output MOM & Classes \\
\hline 0.10 & Class 1 \\
0.35 & Class 2 \\
0.55 & Class 3 \\
0.70 & Class 4 \\
0.95 & Class 5 \\
\hline
\end{tabular}

Figure 1 shows that almost half of the electricity market has high or very high potential for solar energy generation and just $1 \%$ has almost no potential for it. Around 2.108 residential consumers can be classified as consumers with high potential for solar energy generation. It's interesting to notice that only the first stratum has consumers in Class 1 , with the lowest solar energy potential.

TABLE VII. NUMBER OF CONSUMERS PER SOLAR ENERGY POTENTIAL CLASS

\begin{tabular}{lccrrrrr}
\hline \multirow{2}{*}{ Class } & \multirow{2}{*}{ Group } & \multirow{2}{*}{ Stratum } & \multicolumn{5}{c}{ Consumers } \\
\cline { 3 - 8 } & & & Class 1 & Class 2 & Class 3 & Class 4 & Class 5 \\
\hline \multirow{3}{*}{ Residential } & 1 & 1 & 96 & 223 & 542 & 447 & 606 \\
& 1 & 2 & - & 318 & 681 & 522 & 409 \\
& 1 & 3 & - & 93 & 62 & 93 & 31 \\
\hline Total & & & 96 & 634 & 1.285 & 1.062 & 1.046 \\
\hline
\end{tabular}

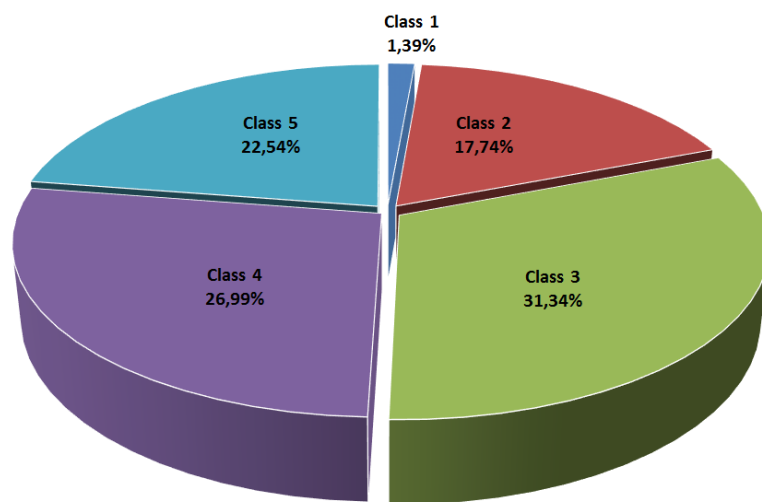

Figure 9. Residential Energy Market per Solar Energy Potential

From Table 8, it can be noticed that Class 3 (medium potential) responds for $31 \%$ of the electricity market, followed by the Class $4(27 \%)$ and Class $5(22,50 \%)$. The market with consumption interval ranging from 80 to $220 \mathrm{kWh} / \mathrm{month}$ the solar energy potential is concentrated in the Class 3 , meanwhile for the consumption range 220 to $500 \mathrm{kWh} / \mathrm{month}$ the Class 2 and Class 4 responds for more than half of the electricity market.

TABLE VIII. ELECTRICIY CONSUMPTION PER SOLAR ENERGY POTENTIAL

\begin{tabular}{|c|c|c|c|c|c|c|c|}
\hline \multirow{2}{*}{ Group } & \multirow{2}{*}{ Stratum } & \multirow{2}{*}{$\begin{array}{c}\text { Consumption } \\
\text { Interval }\end{array}$} & \multicolumn{5}{|c|}{ Estimated Consumption } \\
\hline & & & Class 1 & Class 2 & Class 3 & Class 4 & Class 5 \\
\hline 1 & 1 & $\begin{array}{lll}1-0 & \text { A } & 80\end{array}$ & 70 & 164 & 397 & 327 & 444 \\
\hline 1 & 2 & $2-81$ A 220 & - & 537 & 1.151 & 882 & 691 \\
\hline 1 & 3 & 3- 221 A 500 & - & 350 & 233 & 350 & 117 \\
\hline & & & 70 & 1.051 & 1.782 & 1.560 & 1.251 \\
\hline
\end{tabular}

\section{B. TOU Impact Analysis - Results}

Considering the tariffs approved by ANEEL in 2017, the electricity costs for each consumer sampled were calculated, considering both the flat and the TOU tariff. And through this procedure it was defined the best tariff option for each consumer. Figure 11 shows the market share for each tariff, and it can be observed that only $25 \%$ of the electricity market would migrate to the time-of-use tariff.

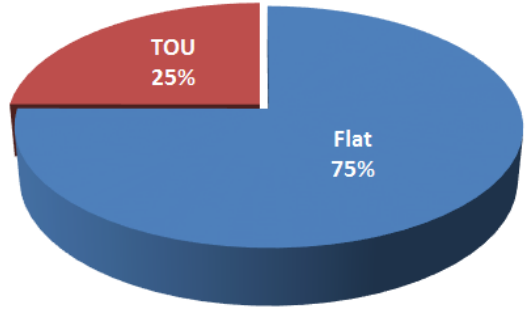

Figure 10. Residential Energy Market per Tariff Type

Table 10, Figure 12 and Figure 13 presents tariff choice per consumption interval. The fist stratum is the one with the highest migration impact, $30 \%$ and the third stratum has the lowest one, around $14 \%$. The only difference between market share for each tariff per consumption interval relies on the third stratum, that has highest participation on the flat tariff market than in the TOU market.

TABLE IX. ELECTRICITY CONSUMPTION PER TARIFF 


\begin{tabular}{|c|c|c|c|c|c|}
\hline \multirow[b]{2}{*}{ Class } & \multirow[b]{2}{*}{ Group } & \multirow[b]{2}{*}{ Stratum } & \multirow{2}{*}{$\begin{array}{c}\text { Consumer } \\
\text { Interval } \\
\text { (kWh/mês) }\end{array}$} & \multicolumn{2}{|c|}{ Estimated Annual Consumption } \\
\hline & & & & Flat Tariff & White Tariff \\
\hline \multirow{3}{*}{ Residencial } & 1 & 1 & \begin{tabular}{|lll}
0 & A & 80
\end{tabular} & 978.653 & 423.399 \\
\hline & 1 & 2 & 81 A 220 & 2.409 .570 & 851.575 \\
\hline & 1 & 3 & 221 A 500 & 898.631 & 151.458 \\
\hline Total & & & & 4.286 .854 & 1.426 .432 \\
\hline
\end{tabular}

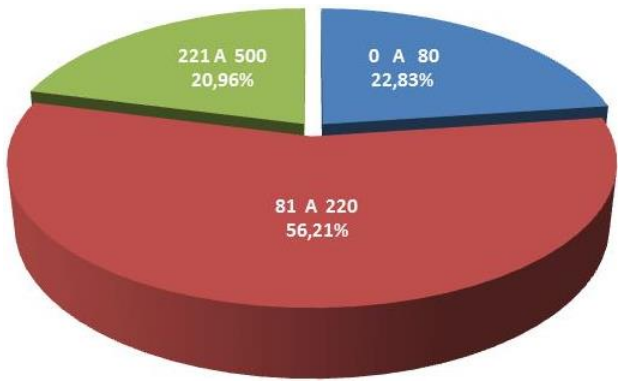

Figure 11. Flat Tariff Share per Consumption Interval

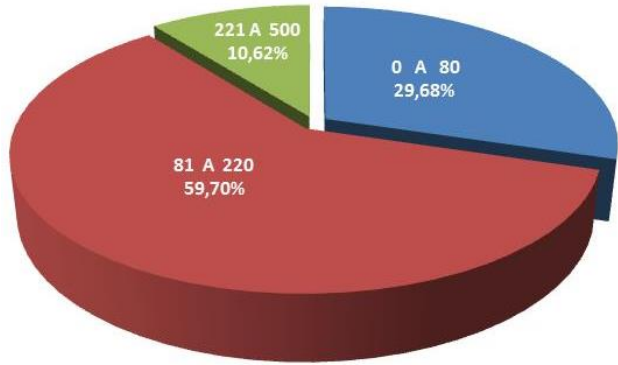

Figure 12. TOU Tariff Share per Consumption Interval

Crossing the solar energy potential analysis with the TOU impact analysis, it aas estimated that $44 \%$ of the maket that would migrate to the TOU tariff has medium potential for solar energy generation and therefore, could combine both decisions. For the market share which remained in the flat tariff, 33,40\% showed high potential for solar energy generation and could benefit from it. It is possible conclude that the market share that migrated to the TOU tariff has more potential for solar energy use than the market from the flat tariff. From Table 10 it's possible to see that most of the consumers with low potential for solar energy generation migrated for the TOU tariff, meanwhile consumers with higest potential remained in the flat tariff.

TABLE X. TARIFFs Class VERSUS SOLAR ENERGy POTENTIAL

\begin{tabular}{lrr}
\hline Class & Flat Tariff & White Tariff \\
\hline Class 1 & $33,0 \%$ & $67,0 \%$ \\
Class 2 & $73,4 \%$ & $26,6 \%$ \\
Class 3 & $64,8 \%$ & $35,2 \%$ \\
Class 4 & $85,0 \%$ & $15,0 \%$ \\
Class 5 & $80,9 \%$ & $19,1 \%$ \\
\hline
\end{tabular}

\section{CONCLUSION}

The study aimed to develop an analysis of solar energy generation potential and TOU impact analysis using residential consumers daily load curves information. The study was performed for a small city called São Luiz do Paraitinga, but the same method can be replicated considering bigger cities as well. To implement the study computational inteligence and statistical inference techiniques were applied. Bussiness days and non-working days typical load curves were concieved for each consumer sampled providing valueable information, not just for tariff impact and solar energy potential analysis but also to support stakeholder and consumers during the decision making process. Interesting conclusions can be taken from the study. The city has high potential for implementation of solar energy generation projects, from rooftop arrangements to micro or mini solar generation plants that could fulfill the power generation needs for its population. Most of the city electricity market has medium to high solar energy generation potential. The introduction of the TOU tariff would promote a migration of around $25 \%$ of the city electricity market to the new tariff, without any change on its consumer behavior (without any load modulation), therefore providing no benefit to the power system.

\section{REFERENCES}

[1] M.B.C. Mello, "Avaliação de Projetos de Investimentos com Opções Reais: Cálculo do Valor da Opção de Espera de um Sistema Fotovoltaico Conectado à Rede", Master Thesis, Pontifical Catholic University of Rio de Janeiro, Dept. Management, 2015.

[2] G. T. Esteves. Energy Generation, Rural Electrification and Smart Grid Solutions at the Brazilian Power Sector: An Overview of the Improvements, Bottleneck and Incentives Established through the New Regulatory Framework (2009-2013). Micro Perspectives for Decentralized Energy Supply: Proceedings of the International Conference. Bangalore: p. 147-151, 2015.

[3] C. Bauner, C. Crago. Adoption of residential solar power under uncertainty: Implications for renewable energy incentives. Energy Policy. Vol. 86, p. 27-35, 2015.

[4] I. Ritzenhofen, S. Spinler. Optimal design of feed-in-tariffs to stimulate renewable energy investments under regulatory uncertainty - A real options analysis. Energy Economics. Vol. 53, p. 76-89, 2016.

[5] P. C. Nogueira, "Análise da inserção de geração solar fotovoltaica em grandes consumidores do Rio de Janeiro: um estudo de caso," Masters dissertation, Dept. Electrical Eng., Pontifical Catholic University of Rio de Janeiro, 2016.

[6] D.L. Carmo, R.C. Souza, M.N. Frota. Identification of potential users of photovoltaic conversion. Renewable energy and power quality journal, 2015. p. $1-6$

[7] D. L. Carmo, "Metodologia para identificação de potenciais usuários de conversão fotovoltaica: estudo de caso de grandes clientes de uma concessionária de energia elétrica", Masters dissertation, Pontifical Catholic University of Rio de Janeiro, Dept. Metrology, 2014.

[8] ANEEL. PRODIST http://www.aneel.gov.br/modulo-2

[9] ANEEL. TARIFF. http://www.aneel.gov.br/resultado-dos-processostarifarios-de-distribuicao

[10] INMET. http://www.inmet.gov.br/portal/

[11] K.Tamás, L.T.Kóczy. Mamdani-type inference in fuzzy signature based rule bases. 8th Int. Symp. Hungarian Res. Comput. Intell. Informatics, vol. 1,2007 , p. 2 